\title{
"I Have a Voice-Hear Me!" Findings of an Australian Study Examining the Resettlement and Integration Experience of Refugees and Migrants from the Horn of Africa in Australia
}

\author{
Eileen Pittaway, Chrisanta Muli, and Sarah Shteir
}

\section{Abstract}

Using the lens of "integration criteria" developed by Ager and Strang, this article presents the findings of a project documenting the resettlement and integration experiences of refugees and migrants from the Horn of Africa ( $\mathrm{HoA})$ in Australia. While refugees have enormous potential to integrate successfully, and many do, there are obstacles which persist. These include: trauma; separation of family members; lack of adequate on-arrival information and support; difficulties with language acquisition; lack of access to appropriate and affordable housing; lack of education support; discrimination in the work force; conflict within families; racism; and violence against women.

\section{Abstract}

À travers le prisme des "critères d'intégration" mis au point par Ager et Strang, cet article présente les résultats d'un projet documentant les expériences de réinstallation et d'intégration, en Australie, de réfugiés et de migrants de la Corne de l'Afrique. Bien que les réfugiés ont un énorme potentiel à s'intégrer avec succès, et que nombre d'entre eux y parviennent, des obstacles persistent néanmoins. Parmi ceux-ci figurent les suivants : traumatismes; séparation des membres de la famille; manque d'information et de soutien adéquats à l'arrivée; difficultés d'apprentissage du langage; manque d'accès à un logement convenable et abordable; manque de soutien à l'éducation; discrimination sur le marché du travail; conflits au sein des familles; racisme; violence contre les femmes.

\section{Introduction}

It is estimated that over one million people from the Horn of Africa (HoA) are living in refugee situations in East Africa. ${ }^{1}$ Each country in the region, with the exclusion of Djibouti, has produced as well as hosted refugees. The majority of these live in "protracted refugee situations," defined as those "in which refugees find themselves in a longstanding and intractable state of limbo. Their lives may not be at risk, but their basic rights and essential economic, social, and psychological needs remain unfulfilled after years of exile."2 Refugee camps are often violent; food, education, and medical services are at a minimum. Many children and young people are born in these refugee camps and have known no other life. People suffer from serious challenges to their cultural identity and their ability to maintain family and community life. ${ }^{3}$

Each year Australia resettles approximately six thousand mandated refugees and six thousand special humanitarian entrants from refugee-like situations as part of its program of migration. Of the refugee component, 10.5 per cent of places are held for women at risk, a special visa category for women and their children who have experienced extreme risk and who are vulnerable to future violence. In response to requests from the United Nations High Commissioner for Refugees (UNHCR) to assist refugees from protracted situations, between 2003 and 2005, the Australian government increased the proportion of refugees resettled from African nations from around 33 per cent of its annual intake to over 70 per cent, with the majority coming from the Horn of Africa. ${ }^{4}$ Since 2002 more than 20,000 refugees from the HoA have been resettled to Australia. The majority of those came from Southern Sudan. 
Resettlement is an opportunity to regain and rebuild shattered lives. Despite experiences of persecution, violence, forced migration, and loss of family and home, many refugees from the HoA are settling successfully and not only working for themselves, but also assisting their communities both in Australia and in Africa. They are succeeding in their new lives, and contributing to the richness of the social, cultural, and economic fabric of Australia. The resilience and adaptability of refugees and refugee communities is evident in the way refugees from the HoA seize the opportunities they are given in resettlement, while carrying with them the horrendous experiences of their past. Members of the mainly anglophone countries of the Horn of Africa living in Australia have come together to form the Horn of Africa Relief and Development Agency (HARDA). It provides a forum where members work together to assist refugees and migrants as they establish new lives.

There are, however, major challenges in the process of settling into a new and different country and culture. Unfortunately, in the case of migrants from the HoA, this has resulted in unprecedented negative media and political attention. In October 2007, this population in Australia was dealt a significant blow when the then Minister for Immigration, Kevin Andrews, issued a media release and conducted several interviews in which he announced that Australia was cutting its humanitarian intake from Africa because these communities, particularly the Sudanese community, were experiencing significant settlement problems and not integrating well into Australian society. ${ }^{5}$ Although the Minister made particular reference to Sudanese refugees he spoke broadly about problems for all refugees from Africa, homogenizing vastly different ethnic, cultural, and social groups. The resettlement intake from Africa has subsequently fallen back to just over 33 per cent. The repercussions of this announcement continue to reverberate negatively in African communities, exacerbating existing community stress and tensions within and among diverse African communities and the broader community. There is little evidence to support these contentions, and the problems experienced by new arrivals from the Horn of Africa reflect many of the problems in settlement experienced by previous refugee intakes from many different countries. The reasons for the discrimination against refugees from African nations is beyond the scope of this paper, but is important as it provides the context in which the community is struggling to achieve integration. It has been suggested that the obvious difference in appearance and culture of these new arrivals has made the problems which they are experiencing more visible. Australia does not have a history of migration from African nations, and relationships between Australian indigenous people and the mainstream community are often problematic. The international political climate of fear and the increased focus on border protection are also discussed as contributing factors. This project was initiated by HARDA as a response to these issues and to seek some answers to the questions. .

To date, little detailed qualitative research has focused on the resettlement and integration of refugees from the HoA, either in Australia or overseas. There have been significant studies of some particular groups of refugees from the HoA, for example the Somali Bantu in the US 6 and Ethiopian and Somali in Canada. ${ }^{7}$ Other studies have focused on specific aspects of resettlement, such as youth ${ }^{8}$ and women, ${ }^{9}$ and some excellent studies of resettlement experience have been undertaken in Australia. ${ }^{10}$ However, little work has been published about the integration experience of a large population who self-identify as members of the HoA community. The findings presented here originate from a project established to fill this significant knowledge gap. A strength of the study is that is demonstrates the linkages between the many aspects of settlement which are often examined independently. This information will foster better understanding of refugees from African communities living in Australia and other countries of resettlement. It highlights the problems experienced by refugees who have lived for extended periods in protracted refugee situations, as they sometimes struggle to adapt to a new life in a world which has changed dramatically since they were forced to flee their home countries.

\section{Settlement Service Provision in Australia}

Successful settlement is a key objective of a range of services provided by the government to assist resettled refugees in their first years in Australia under the Humanitarian Program. ${ }^{11}$ The most important of these is the Integrated Humanitarian Settlement Strategy (IHSS), which provides initial settlement support and orientation to newly arrived entrants for a period of six months. These services include on-arrival reception and assistance; accommodation services; case coordination, information, and referrals; short-term torture and trauma counselling; and emergency medical needs. ${ }^{12}$

Humanitarian entrants are then referred to general settlement services provided through migrant service agencies and organizations funded under the Australian government's Settlement Grants Program. ${ }^{13}$ Other settlement services are provided by community groups, faith-based services, and non-government organizations. People who enter Australia as part of the resettlement program are entitled to these services for up to five years, after which they are expected to access mainstream services. While the quality of many of these services is excellent, they are not 
consistently offered across the areas in which refugees are settled, and they are often insufficiently resourced to meet their needs.

IHSS services are only available to those people who enter Australia on a refugee visa. Humanitarian entrants are eligible for IHSS services on a "needs basis."14 This can cause great hardship for newly arrived entrants, who usually come from the same camps and urban refugee sites as those who come as refugees, and for their families who have sponsored them and who bear the responsibility of assisting them in settlement. It is important to note that 70 per cent of refugees from Sudan entered Australia on Special Humanitarian Visas.

\section{Methodology}

This paper is based on a research report that documents the resettlement and integration experiences of refugees and migrants from the HoA in Australia. ${ }^{15}$ The project was instigated and funded by the Horn of Africa Relief and Development Agency (HARDA), in partnership with the Centre for Refugee Research, University of New South Wales, Australia. Community consultations and semistructured interviews were conducted with a total of eightythree people, thirty-seven men and forty-six women, aged between eighteen and fifty, the majority in the twenty-five to forty age bracket. Forty-six participants were from Sudan, and the balance were evenly spread from Ethiopia, Eritrea, and Somalia, with two from Kenya and one from Uganda. The majority now live in metropolitan Sydney. Participants were identified by community leaders from HARDA and non-government service providers. They included two male and two female community leaders, four people employed in a professional capacity, and eight adult students. Six participants who had entered Australia as refugees had employment as bilingual workers with settlement service providers. The majority of participants were unemployed or underemployed. A range of family compositions were represented, with five single men, two single women, nineteen women representing female-headed households, and fiftyseven people who were part of married couples with children. Twelve people had been in Australia for more than five years, fifty-eight had arrived in Australia between five and two years ago, and thirteen had arrived two years before the study took place (2009). All but two participants came to Australia as refugees, and the average time spent in refugee camps or urban refugee sites was nine years. As noted below, the findings from all groups were remarkably consistent around the key areas of settlement needs and outcomes. Community leaders, community workers, and men and women shared similar concerns and aspirations. The major difference of opinion was around the issues of women's rights and the rights accorded to children in the Australian social and legal systems. These were more openly discussed by community members who had come to Australia in the last five years.

A mix of interviews and community consultations were used to collect the data. A qualitative methodology was deemed suitable for this study because this approach builds on "a complex, holistic picture, analyses words, reports detailed views of informants, and conducts the study in a natural setting." 16 Qualitative research used participant responses as a starting point from which broader analytical categories were drawn. ${ }^{17}$ The rights-based community consultation methodology used narrative research techniques to document issues concerning refugee communities. The focus of the method is the collection of information from often vulnerable populations in a way that is empowering, not harmful, and not exploitative, and that has the potential for bringing about social change. ${ }^{18}$ Semi-structured, in-depth interviews were used to collect additional data from individual participants. The participants were asked to share their experiences of settlement in Australia, the things which they found positive, and the challenges which they faced. The interviews explored beliefs, perceptions, attitudes, and opinions that might not have been exposed during the community consultations. ${ }^{19}$

Many refugee communities in Australia are expressing their frustration at the number of times they are interviewed by service providers, students, and academics, and how little benefit they see from their input. They perceive that what they say is seldom acted upon, leading one participant to exclaim, "We have a voice-hear us." Another talked about "silent screams." This report attempts to honour the commitment to give sound to that voice.

\section{Conceptual Framework}

Integration is a core component and policy goal of many immigration programs, including Australia's, and a widely used concept in the field of refugee and migrant studies. Nevertheless, it remains a contested, controversial and "chaotic" concept. ${ }^{20}$ Castles et al. ${ }^{21}$ have noted "there is no single, generally accepted definition, theory or model of immigrant and refugee integration." The concept of integration as a positive humanitarian endeavour which benefits both the resettling refugee and the host community has in recent times been overtaken by a more sinister concept. Some governments are using the notion of "integration potential" as a criterion for selecting refugees for resettlement, thus placing the responsibility for successful settlement and integration on the shoulders of the refugees.

It is a common principle across many integration programs that "basic knowledge of the host society's language, 
history and institutions is indispensable for integration. ${ }^{22}$ This notion has been implemented through policies which mandate integration programs for refugees. The consequences of non-compliance with the terms and conditions of integration are serious and directly linked to economic, social sanctions. This punitive approach stems from arguments made by theorists, social commentators, and policy makers that diversity, produced by immigration, challenges the social cohesion of society. ${ }^{23}$ It is asserted that ethnic and racial heterogeneity undermines the existence of "common values and purpose in a society, including a sense of belonging and solidarity" required for communication and cooperation between different sections in society. ${ }^{24}$ However, this policy approach marginalizes the importance of a number of key and interrelated dimensions which research has shown to facilitate successful integration. Policy that relies on fostering community relations across different groups will inevitably neglect the psychosocial needs of refugees and interventions required to alleviate structural inequalities. ${ }^{25}$

We argue that this use of the concept of integration is contrary to both the letter and the spirit of the 1951 Refugee Convention, the 1967 Protocol, and the 2001 UNHCR Agenda for Protection. ${ }^{26}$ Resettlement is a protection measure for those refugees who are unable to return to their country of origin or to integrate into the country of first asylum. It is part of the humanitarian response to the international refugee crisis to which many developed countries have committed, in the spirit of burden sharing with those developing countries who host the majority of the world's refugees. As such, providing the services and infrastructure necessary for integration is the prerequisite of inviting refugees to resettle. The Australian government does not support integration criteria as a screening tool for selecting refugees for resettlement. The use of "integration" in this paper is in the spirit of humanitarian endeavour.

Ager and Strang, working with the UK Home Office, have proposed a conceptual framework for understanding and defining integration which addresses many of these criticisms. It is comprised of ten core domains of wide relevance, based on normative understandings of what constitutes successful integration. This framework is used to explore the findings and its usefulness as a tool to explore and inform the settlement process is critiqued. The framework examines key potential indicators of integration, which are: markers of integration, means of achievement of integration, processes of achievement, and facilitators of local integration. Achievement of and access to employment, housing, education, and health are identified as discrete domains and are recognized both as markers of integration and as potential means to support the achievement of integration.
Processes of social connection are broken down into three discrete domains which also determine the achievement of integration: social bonds (with family and other members of their community); social bridges (with other communities, including the host community); and social links (with the structures of the host state). Language and cultural knowledge, and safety and security are identified as discrete domains and considered "facilitators" of local integration. Foundational to all of these is the experience of citizenship and rights. ${ }^{27}$

Ager and Strang suggest that it is problematic to understand attainment in the domains of employment, education, health, and housing as simply an indicator that integration has been achieved or as a quantifiable outcome of the integration process. ${ }^{28}$ This notion of "public outcomes" conceives of integration as having reached the state of "full and equal participation" in social, economic, and cultural life, without regard to the mechanisms which led to it. Ager and Strang argue instead that "progress with respect to one domain supports progress with respect to another."29 Therefore, advancement in every area coexists and complements the others, each serving as potential means to support the achievement of integration itself.

As noted above, this framework identifies three forms of social connection as fundamental to integration: "social bonds" (with family and other members of an identified community); "social bridges" (interactions and networks formed across different communities within society); and "social links" (with structures of the host government). In the integration models described earlier, social bridging is preferred over social bonding and social linking as the means by which refugees can access services and institutions and therefore become fully integrated. In their conceptual framework of integration, Ager and Strang highlight the need to recognize the interdependency of multiple domains in the process of integration. For example, the lack of quality education in camps has a direct impact on the ability of children to engage in the education system in Australia. Lack of recent and relevant work experience makes finding employment difficult. Achievement of the main markers and means of integration is often reliant on a positive engagement in the three defined processes.

The findings and recommendations have been loosely grouped according to these domains. While providing an extremely useful framework, it must be acknowledged they do not encapsulate the full complexity of the experience of new arrivals. Nor do they identify all of the imperatives which contribute to or hinder successful settlement and integration. In particular they do not explicitly acknowledge the impact of pre-arrival experience as a refugee on the ability to settle or the role of expectations brought by newly arrived 
refugees. Staff from Foundation House, Victoria, ${ }^{30}$ amongst others, have noted that the issue of family reunification and mental health issues, in particular those linked to torture and trauma, are not given prominence. While these may be implicit, we believe they need to be clearly articulated to enhance the use of the framework as a tool.

With those caveats, it is still considered that the framework can indicate the areas of settlement which service providers need to focus on to improve the experience of new arrivals. This knowledge can inform policy consideration and service provision. It provides an effective tool, where one has not been previously available. The decision to use this framework was made towards the end of the project and was not reflected in the design of the semi-structured interviews or consultation trigger questions. It is therefore significant to see how closely the research findings can be correlated with the domains identified in the framework. Refugees raised a number of additional issues, which are presented here in order to contribute to building a more critical understanding of integration. The quotes used in this paper come from the research report which was the outcome of the project initiated by HARDA. Some participants spoke English; two of the researchers, one female and one male, were from an African background and spoke a number of languages common to the participants. They translated the interviews which they did. Interpreters identified and trusted by HARDA were used at the community consultations and for a small number of interviews. Minor grammatical changes have been made to some quotes to ensure meaning, but whenever possible the voice of the refugees has been used verbatim.

\section{Pre-arrival Factors Which Impact on Settlement and Integration}

It has been argued that the protracted refugee situation places people in a position of liminality. The experience takes people from a familiar, predictable past toward an alien, unknown future, where all certainties are questioned, including their own roles and status, identities, and relationships. ${ }^{31}$ Sudanese Dinka scholar Francis Deng describes this effect among the Dinka displaced from Sudan: "They are literally fish out of water ... they have been deprived of what has made them productive, healthy, dignified human beings." Refugees from the HoA face significant challenges to integration due to their cultural, socio-economic, and religious backgrounds, which can be fundamentally different from the normative backgrounds of the host population. ${ }^{32}$

It is therefore important to acknowledge the impact that pre-arrival experiences of hardship, loss, trauma and torture may have on resettlement and integration.
I walked 3 months from Sudan to Ethiopia ... I saw colleagues, friends and family die along the journey, we had no access to food, no water, no medical assistance, no security. There was a lot of fear, if you don't walk hard you die. Girls were killed and raped by the soldiers. By the time we got to Ethiopia we were skeletons ... we looked like skeletons. - Sudanese refugee

The loss of life, loss of family members, loss of freedom, and the loss of their material possessions were all discussed at length by the participants.

Everyone lost someone, my whole family was killed during the war. The last time I saw my mother and sister was 18 years ago, and they were being rounded up by the militia. I ran away it was an unbelievable experience people died ... many people died. - Sudanese refugee

Instead of security and protection, many refugees found that the camps or refugee sites in cities were as dangerous as the places they had fled from.

Kakuma camp was horrible, horrible, dangerous, hot and dusty55 degrees, not enough food or water, and danger everywhere, people killed, women raped, no safety anywhere, nothing to do, no proper school for the children, the hospital was a tent. - Eritrean refugee

Once granted a resettlement visa, refugees dreamt of safety and security which would include housing, education, and freedom amongst friendly and supportive people who had invited them and would welcome them into their country.

I am going to paradise, I will be staying in a beautiful house, I will learn English and will be living with friendly, supportive people who accepted people to come to their country. I expected everything to be good. - Sudanese refugee

For some these expectations have been achieved; for others, the reality is still a distant dream. Sadly, many are realizing that life in Australia will never live up to the expectations they had when they first thought of escape to a new and secure life for themselves and their families.

People think life in Australia will be good or easy. You are peaceful, have a house, the kids go to school and got something to do. This is not happening. People don't know it will be difficult here. They need awareness to know it won't be easy. - Sudanese refugee 


\section{Markers and Means of Achievement and Integration}

The four markers of means of employment, housing, education, and health were identified by all participants as priority areas, regardless of how long they had been in Australia or which country they had come from.

\section{Employment}

Gaining employment affects identity, status, and a feeling of worth. It allows people to build a new life in Australia and to fulfill obligations to family still trapped in refugee camps overseas. However participants reported that skills they bring with them are not easily transferable to a modern, developed work environment such as Australia's which is vastly different to where they have come from. Many faced serious discrimination in the employment market because of their lack of "Australian" work experience. This meant that they were unable to access an income to secure financial independence.

We spent a lot of time looking for job. You go and they ask you for a resume, you don't have it .... they ask you for Australian work experience ... you have just arrived in Australia. I don't know how they want us to get experience if they do not want to give us a job. -Sudanese refugee

A further barrier to securing employment is the nonrecognition of the educational and professional qualifications that the participants brought with them to Australia, a problem which refugees share with many other migrants to Australia. However, an additional factor for people who have spent years in protracted refugee situations is that their qualifications are often out of date, and people have not had an opportunity to practice their professions.

\section{Housing}

The experiences of loss of home and years in camps or in transit make housing crucial to an overall sense of safety and security.

I could not find a place to live. It took me 3 months to find a place. It was a terrible experience because I have been living in the bushes, and in the refugee camps in Africa ... But when I come to Australia first of all there was no explanation why I could not be getting that house. They just say that your application has been refused. - Sudanese refugee

A housing crisis in Sydney has led to exceptionally high rents. This has forced families to share accommodation and has resulted in overcrowding. Tenants live in fear of landlords finding out how many people are sharing a house.
Refugees risk retraumatization if they are evicted, because it means they have lost everything all over again.

Appropriate housing for the participants also included the physical size of the house, as well as the quality of the accommodation available. In some cases participants described how the lack of suitable housing resulted in their family being separated.

Australians have 2 children or 3 . I need 4 bedroom house at least for my 6 children. A big family is being denied these days when you go for housing. - Sudanese refugee

\section{Access to Education}

The high expectations that many parents hold for their families are focused on their children's educational attainment, yet many of the children are failing to adapt to school. Parents reported that insufficient attention is given to the previous levels of education that their children had received.

Some of our children have never been to a class or have only gone till year 2 or 3, because we have been running from the war, moving from place to place. When you get here they put you in year 10 because of their age. - Sudanese refugee

They discussed the lack of teacher training, the impacts of trauma on children, and some teachers' lack of preparedness to work with refugee families.

Teachers should be trained to work with refugee children. These are children that need a lot more than regular students in terms of support and understanding. This would make the transition easier and vital for resettlement. - Somali refugee

Frustration was expressed at the lack of information about the school system and by insufficient support for learning in the school environment. They were particularly distressed by the isolation and exclusion that some of their children were facing within the education system.

I always felt like the odd one out in school. It was difficult to make friends with other kids. I looked different, and the kids in school looked at me different. —Somali refugee

Appreciation was expressed for education and training opportunities for adults, many of whom had never had the opportunity to attend school.

I could not read or write, but look at me know-I can talk in English and now I am learning to read and write in English. - Sudanese refugee 


\section{Health Services}

Few participants report problems obtaining physical health services, and access to health care was contrasted favourably with the lack of access to doctors in camps and refugee situations. However, the urgent need for mental health services was discussed at length. Many reported experiencing feelings of sadness, loneliness, depression, trauma, stress and confusion.

I cry every night-I remember the torture, I still feel the pain. -Somali refugee

When you arrive as new arrival and you are not being shown how to follow your life you feel depressed ..., confused, stressed, traumatised, depressed. You don't know where to go, what to do ....-Sudanese refugee

Some were aware of and appreciative of the services that did exist, and described the relief that could come from receiving appropriate assistance. However, they reported that it was often difficult to get assistance when and how they needed.

I cannot mentally settle in this country .... here it is new survival. How can you cope, you get depressed and anxious and feel very lost .... Many of us are scared of losing our identity. - Somali refugee

Particular concern was expressed about the mental health of unaccompanied minors.

We don't have parents, no one here, no friends, we are alone, what are we going to do? We have to start again. - Sudanese refugee

Many made the comment that generalist service providers did not encourage them to talk about the bad things that had happened. They expressed the need to tell their stories as part of the healing process that they needed to integrate into the community.

This is the first time I have told anyone about this-this is the first time I have been allowed to talk. -Ethiopian refugee

There are long waiting times and lack of interpreter services. Resilience needs nurturing. The lack of sufficient health services and treatment that caters directly to the needs of refugees inhibits and challenged their integration and resettlement process.

\section{Processes of Integration}

Social Bonds with Family and Other Members

of Community

Participants defined support from community members who understood and had similar refugee experiences themselves as fundamental to their settlement and integration.

I need to hear my own language, to know where to buy our food. What day can women go to the mosque? I want someone who knows and does not have to have everything [about the cultural background] explained. -Ethiopian refugee

However it was noted that the time pressures of re-establishing lives in a new country made it very difficult to maintain the customs and networks from the home country. The differences in culture, custom, and law also posed significant challenges and made the maintenance of community difficult.

I am confused with the meaning of community in Australia. I do not know how I can divide myself into being a member of my Eritrean community and at the same time being a part and parcel of my new found home Australia. - Eritrean refugee

In response to this need, many African community organizations have been founded. However, there is a continual struggle by members to respond to the demands of the new society and at the same time fulfill their individual goals needs.

Operating African Community organizations from the perspective of its members in a western law framework is the hardest thing we African Community leaders face in Australia. - African community leader, Ethiopian refugee

Huge expectations are placed on these organizations by community members and service providers. They receive little funding and are often staffed on a part-time basis or by volunteers. They are expected to be the media face of their community, and to respond to requests for information from a range of government departments and politicians.

We are burning up-we do not have the time to do what we want to do, which is to help our community. I am paid part time and yet I work all the time, and at night and at the weekends. -Community worker, Sudanese refugee

Despite these problems, communities do flourish and support each other. However, the notion of community is complex, and it is important that the background and 
wishes of individual refugees are taken into account when placing them for settlement.

I was the only one from my tribe in [a small country town in Australia]. There were people from another tribe-they had killed my husband. There was no-one there for me. The white people told me I had to mix with the other Africans-they said "you are all from Sudan." I ran away to Sydney to find some of my people. I left all of my things there. - Sudanese refugee

Other serious challenges to the maintenance of family and community structures have also emerged. The difference between Australian conceptions of family and traditional roles of husband, wife, and children in communities from the HoA were discussed. Domestic violence was widely reported. Children acquire the English language and a working knowledge of the new culture more quickly than their parents, even if their perception is sometimes distorted by television and misinformation. Roles are reversed and children are often put into the position of "head of family," translating and negotiating with service providers, doctors, and the school.

Children grow up too fast-they have to interpret for their parents negotiating rental agreement-hearing their parents' stories of torture and trauma. - Eritrean refugee

There is confusion about the role of child protection agencies, and the power of youth to challenge the authority of their parents. People felt that they were not given enough information about the social and legal implications of these differences.

Who is the head of the family in Australia? The law should tell us. - Ugandan refugee

The need for family reunion was discussed by all participants. Constant worry about family left behind means that people are not able to focus on their settlement needs.

I arrived in Australia in 2005 and since then, 16 members of my family have died since then in Sudan. This has caused me a lot of trauma and worry for my relatives left behind in Sudan. - Sudanese refugee

People came to Australia having been told that once established here they would be able to apply to have their close family members join them.

My children are in Egypt being taken care of by family members. I worry about them. I was misled and did not include them in my application forms. I think about how I can get them here, otherwise I have to go back.-Sudanese refugee

A further stress and complication is the different definition of "family" held by the Australian government, which is based on the biological. Notions of family responsibility are much broader in many African communities and this is even more important in refugee situations. In the face of so much death and destruction, nephews and nieces are raised by aunts, uncles, or cousins. People informally adopt orphans and bring them up as their own. When they are not recognized by UNHCR and consular officials it causes tremendous hardships. People who arrive in Australia not understanding our narrow definitions of family are often accused of lying and fraud when they try to reunite with family members.

Refugees also carry the burden of supporting those left behind.

I am also supporting my whole family in Sudan, it is not easy but it is my responsibility. - Sudanese refugee

The need to send money back to family in camps is a constant stress and moral obligation. Some participants described their humiliation when they went to request food assistance from charities, and were told that it was their fault that they were hungry - they had no right to send overseas the money that the government gave them to live on here.

I have thrown away my phone-I can not talk to them again. They phone, they need money for medicine for food, they are sick, they are starving. What can I do-I cannot pay the rent here. I cry all day and I cry all night. - Ugandan refugee

The pain of family separation is therefore a major challenge to timely and successful settlement and integration.

\section{Social Bridges between Communities}

I have been here for ten years and I have never once been inside an Australian home - it is strange to us. In our culture we share food with our neighbors. Australians do not do this. - Sudanese refugee

The lack of familiarity with the way of life in Australia, and a lack acceptance from the Australian community had resulted in a strong sense of isolation and loneliness. This has led to a reliance on their own communities, which in turn has led to accusations of anti-social behaviour and unwillingness to mix and to integrate. 
I feel like I don't belong to Australia. Is this where I want to grow old and where my children should grow old? No ... we are not at home here. - Sudanese refugee

Participants expressed a strong need for social intercourse with the mainstream community but sadly this does not happen easily.

I struggle to cope with the isolation and loneliness. You have no one to talk to, no one to share with. You are really isolated. Where we come from we had neighbors and family, here we have no neighbors and no family. Instead we have sub-communities in Australia, small sub-communities that you are not welcome to everywhere. - Somali refugee

The role of the church and the mosque were mentioned as important in bridging the divide between new arrivals and the mainstream community. However even this is not without problems.

The church is our 'home' here, but some of the Australian who live near the church complain because they say we make too much noise singing. There was a picture in the paper of a man with earphones on because of the singing. It was horrible. - Sudanese refugee

Sport is also very important and there are many football and basketball clubs, which are breaking down social barriers between various youth groups from different communities. Racism was identified as a key barrier to integration.

Racism silences communities. - Community worker, Sudanese refugee

I was the odd one out. I looked different and I spoke different. No one spoke to me they all made fun of me and my Somali accent .... One day, as I was coming home from school a group white men started yelling out. "Go back where you came from." I was really scared, I kept on walking and thinking .... If I had the choice then I would but I can't so where do you want me to go back to? - Somali refugee

Community workers described how some people fight racist attitudes, but others internalize them and begin to believe that they are true. When communities are demonized in the press there is even less willingness from banks, police, and schools to assist them.

My little daughter tried to scrub the brown colour from her skin in the bath-she said the children at school were laughing at her.

- Sudanese refugee
Racism had resulted in discrimination when seeking housing and employment opportunities. It was also seen as a root cause of problems with young people who felt marginalized and isolated.

\section{Social Links to Structures of the Host State}

The most important link with the structures of the host state for new arrivals are those structures and services that provide the range of on-arrival and settlement services.

This wonderful person met us at the airport. She took us to the flat, she and her friends made food for us and the next day they came and took us everywhere. Whenever we need help I can call her. We felt so strange and lonely and she was there. That was two years ago. She is now the godmother of my daughter. When her mother died I helped her with the funeral. - Sudanese refugee

However, some participants expressed their frustration about the lack of settlement support they experienced when they arrived in Australia.

We came on a Friday night and they took us to a flat and left us and we just sat in the flat all weekend. We did not know how to cook the food they left, we were scared to go out .... It was Monday before they came to see us and for two days we did not eat-we had only water from the tap. - Sudanese refugee

Fear of police and other authorities is a major barrier to these links as in many countries where they have been the agents of persecution and torture. It takes a long time for some refugees to learn to trust the police, as their initial response is one of fear.

If they see people with a gun they will think they are the enemy. - Sudanese refugee

It was reported that some problems are emerging between the police and refugee youth. The fact that some youth are forming gangs and exhibiting anti-social behavior is causing enormous grief within communities, and they are at a loss as to know how to deal with it. It is a patent failure of engagement with the structures of the host society except in the most negative sense.

There was a strong need for information about the "system" but participants did not want to be looked after like children. They asked for information to be given in a way that would allow them to take control over their own lives. They described being given too much information in the first days of arrival when everything was confusing, and not when they needed it, later on. 
People discussed a perceived lack of coordination between the services offered. This led to confusion and a feeling of not being believed when they had to repeatedly tell their story.

\section{Facilitators of Integration \\ Language}

A major hurdle to resettlement was the lack of English language, and the difficulties experienced in learning a second language, in particular for those who have not been literate in their mother tongue.

I have been here for four years and I still cannot speak English. It is like being in a basket. I can see out but can't join in. I can't do anything. I cannot help my children with their school work. Without English I cannot get a good job. - Somali refugee

Proficiency in the English language was discussed as being vital to gaining employment and the services necessary for resettlement and the rebuilding of a new life in Australia.

You cannot do anything if you don't speak English ... I could not communicate when I first got here. I once got onto a bus and the driver could not understand me. No English no transport. - Somali refugee

\section{Cultural Knowledge}

The differences in culture, custom, and law also posed significant challenges. Adjusting to a new culture had not been an easy task. Participants talked of the differences and misunderstandings between their culture and the new Australian culture hindering their resettlement and integration in Australia.

They do not respect our diversity. — Sudanese refugee

It is sometimes difficult to manage the expectations from our community and the Australian community we live in now. - Somali refugee

The clash in cultures was seen as particularly causing a major challenge in the resettlement of the youth.

My fear is that I am losing the African culture with my children. The kids are losing their culture and are more involved in the Australian culture. - Sudanese refugee

The need for the host community to respect the culture of the new arrivals was also seen as critical.
... If you take in people you should take in their culture and custom, otherwise how they can integrate into the system. - Sudanese refugee

Safety

Safety and security were seen as fundamental to resettlement. Some "felt at home" because they were secure from war, others because they could sleep in peace without fear of being killed.

The best thing about being in Australia is here we have rights and security ... we are secure ... Australian security is not like the refugee camp. —Sudanese refugee

Security was described as not just the security from physical harm, but the security to learn and get an education, the security to rent homes, the security to live a better life than before. Women face particular problems in resettlement, and changing gender roles pose major problems and challenges to their security and cultural space.

You see here women have rights compared to where they came from where they had no rights at all. The men don't want to take it ... in the western countries like Australia women are equal to men, and they have a right to complain you know to the police ... men don't like this, so the women suffer for it and have nowhere to turn. - Sudanese refugee

Some men control their wives by threatening to send them back to the camps or the refugee sites if they do not obey them. Women are not always aware of their rights.

Other women are abused physically and financially. The men take all the money from them .... They can't do anything when the men send the money back to their home countries to do other things ... if they have other wives. After all the men have paid dowry for these women and now they are dumping them. - Sudanese refugee

Many single women and widows come to Australia as part of the Women at Risk program and there were significant reports of ongoing risks for refugee women and girls, from this visa category and more generally. The special needs of this group are seldom acknowledged.

Women who experience domestic violence are often blamed for the abuse-people think it is her fault and even the communities will say 'what did you do this time?' Because the communities are so small everyone will know if you report it and will say "don't go near that woman she is no good." We try to pretend everything is OK. - Community worker, Sudanese refugee 
Women reported that problems come with them from overseas. If it is known that they had to engage in survival sex in order to survive and feed their children in camps then they are likely to be targeted here. Single men will come to their homes and say, "You were a prostitute over there." Sometimes they are raped, but are too afraid to report it to the police. Women who have borne children of rape report that their children are discriminated against, especially if it is known in the community that the child is the child of the enemy.

I am afraid to live in my community because they know what happened to me over there. But I want my community-it is strange here and I am lonely. - Somali refugee

There were also reports of males in the community suffering from guilt and disempowerment because they had not been able to protect their women from abuse. The impact of violence against women reverberates through communities and poses major challenges for successful settlement.

\section{Rights, Citizenship, and a Sense of Belonging}

While described by Ager and Strang ${ }^{33}$ as foundational to integration it was clear that the understanding of rights, citizenship, and belonging took time to develop. It depended on the length of time people had been in Australia and the quality of their first years of settlement. It included the attitudes of the Australian community, their access to good quality settlement services, and their ability to take control of their own lives.

Australia gave me rights as a black, Muslim woman. I am proud to be who I am. - Somali refugee

You get to vote without fear of persecution and allow for people to hear your voice. - Sudanese refugee

I wake up everyday with a choice to do things. A choice! I have a choice to be in charge of my life ... a choice to make a good life for myself and my family. - Somali refugee

Some people did not want to be identified as refugees once they had settled in Australia, while others thought that they would always see themselves as refugees.

It is easy for people to say that I am Australian, but I am not. I am and will always be a refugee. So I better maintain my Somali culture so that I have some identity. Culture is special because it is part of your identity ...- -Somali refugee
Other participants understood that while they themselves might never be able to fully enjoy the opportunities, it was possible for their children.

It is too late for the older children to get to University-they missed too much education in Kakuma camp. They are going to TAFE, they will do well and get good jobs-but my grand children-they will be doctors and lawyers!! — Sudanese refugee

Participants noted that citizenship and belonging was not a one-way street in which the refugees are just grateful recipients. Their new community also needs to acknowledge that they have positive contributions to make.

So many of our youth are going into nursing - it is what they can do with the education they have had. Others are going into aged care. They are working in shops, studying at TAFE and University, doing so much. We are doing jobs Australians do not want, we are opening our own businesses, dressmakers, hair braiding and many other things. We are working as community workers, teacher's aides and bi-lingual workers. We are doing so much. -Sudanese refugee

While the participants in the study came from a diverse range of backgrounds and had been in Australia for different lengths of time, the findings from each grouping were remarkably similar. Problems in learning English, finding secure and appropriate housing, and finding employment which paid an adequate wage and afforded a level of dignity were discussed by all participants as the biggest challenges they had to face. Those who spoke English prior to arrival and whose professional qualifications had been recognized in Australia had settled most successfully and reported a higher level of satisfaction with life in Australia. Those who had been in Australia longer had achieved a higher level of integration as measured by the Ager and Strang model than newer arrivals, but often this was at the cost of lowered expectations for the future. This was discussed in terms of losing hope of achieving satisfactory employment, of the realization that they would probably not achieve home ownership, and of losing hope of acceptance by the mainstream Australian community. Ambition was often transferred to children, and several participants expressed a desire to return to their homeland. Problems experienced in bringing family members to Australia and the negative impact that this has on the settlement experience was discussed by eighty-one of the eighty-three participants A deeply felt disappointment expressed by nearly 50 per cent of participants was what they perceived as a lack of acceptance by the Australian community and feeling of not belonging. 


\section{Conclusion}

It is obvious from the findings of this study that refugees and migrants from the HoA have enormous potential to settle and integrate successfully into Australian society and are already contributing significantly to our social, economic, and cultural life. They know the challenges their community faces, and what needs to be done to overcome these.

We might as well not bring them [refugees] here if we can't support them, we are not doing them any benefits ... all they need is someone to avail this opportunity to them. - Sudanese refugee

Refugees come to Australia with capacity and capabilities. With effective service provision, their natural resilience can be nurtured and can grow. While many of the problems experienced by refugees, such as language acquisition, recognition of overseas qualifications, rental problems, and intergenerational problems are common to other migrants, there is a significant difference for people who come to Australia as refugees. The horrors of persecution, loss of family and homeland, the violence of flight, and the stark conditions in refugee camps take a long time to heal. People are often vulnerable; the need for security is critical. The meaning of home as a place to rebuild shattered lives has incredible importance. The need to maintain family and culture in a new country has enormous significance. People feel the need to be able to contribute to their new country, to retake control of their own lives, to regain their dignity and their freedom.

While the Australian government might understand the resettlement program as a part of our humanitarian response, many people in the community and some politicians do not perceive it in this way. If new arrivals have obvious problems in settling into their new country, this will be used by some to criticize the entire community and Australia's program of resettlement. It is therefore essential that the settlement services detailed above are appropriate and effective, both for the well-being of the new arrivals and for promotion of community harmony. The findings of this study clearly illustrate that in many cases this is not the case. It also is essential that services available to refugee entrants be available for Special Humanitarian entrants as well. As part of its international obligation to the protection of refugees, and to enhance social cohesion in Australia, the government has an obligation to create a social context for successful integration. The provision of improved settlement services assists in this endeavour.

The model of integration developed by Ager and Strang proved to be invaluable in understanding the experiences of the communities from the Horn of Africa resettled in Australia and providing guidance for future service provision. New arrivals have identified serious problems accessing appropriate employment, housing, education, and health services which are described as both markers and potential means to integration. It is obvious that the process of integration needs attention. The social connections are at times extremely weak and flaws in the system make it hard to either build or maintain these. Stresses within communities make social bonding difficult to establish and maintain. Bridges with other communities are rare and difficult to navigate. Social links with the structures of host states are fraught with problems, and these are exacerbated by lack of English and understanding of the new social structure. The facilitators of integration need attention. New arrivals are having problems acquiring sufficient English-language skills and mediating mutual cultural understandings. While safety and security is a major benefit to new arrivals, it is not enjoyed by all, in particular by some women. It would appear that while the foundation stones of rights and citizenship are firmly in place, misunderstanding of how these apply is causing confusion and hardship, rather than providing solid bases for successful settlement.

The refugees who felt that they were successfully settled reported positive outcomes in each of the domains mentioned in framework. While experiences differed, the majority felt that they belonged and were contributing to Australian society. They had achieved family reunion, and were satisfied with their access to employment, housing, education, and health services, including treatment of torture and trauma. This does not mean that they had not experienced problems in the past, or that they did not wish for improvements in the future, but for the time being they felt that they were in a good position relative to other migrants, if not to mainstream Australians. They had a good command of the English language, and had social links with all three areas of social connection. Without fail, they had expectations that their children would exceed their social status and levels of integration.

In keeping with the context of analysis, comprehensive recommendations were made and grouped according to the ten suggested domains of successful integration and taking into account the pre-arrival experiences of refugees. ${ }^{34}$ While Australia is a world leader in refugee settlement service provision, there are gaps and shortcomings in both the models and the service provided. The most obvious problem is in the inconsistent spread of these services within metropolitan areas, and in particular in regional and rural areas. We now have a deeper understanding of the nature of protracted refugee situations and the impact of these on the settlement experience of refugees. The impact of the refugee experience on children and youth is well documented. The nature and extent of family violence and breakdown was 
discussed by a large majority of the participants and must be addressed in future service provision. It is important that knowledge and understanding of mistakes made and gaps left in service provision be acknowledged. These must be combined to provide improved opportunities for refugees invited to make Australia their home. The Ager and Strang model proved to be an effective tool and one which has the scope to be expanded and refined to inform future resettlement policy and practice.

\section{Notes}

1. AllAfrica.Com, http://www.allafrica.com/stories/201006200017 .html (accessed 1 August 2010).

2. "Protracted Refugee Situations," UNHCR, Executive Committee of the High Commissioner's Programme, Standing Committee, $30^{\text {th }}$ Meeting, UN Doc. EC/54/SC/ CRP, 14: June 10, 2004: 2.

3. G. Loescher et al., eds., Protracted Refugee Situations (Tokyo: UNU Press, 2009); and UNHCR, http://www.un.org/ events/tenstories/06/story.asp?storyID=2600 (accessed 14 August 2009).

4. Department of Immigration and Citizenship, Australia, http://www.immi.gov.au/media/fact-sheets/60refugee .htm\#c (accessed 26 July 2010) .

5. K. Andrew, "Refugee and Humanitarian Intake 2007-08," media release, 2007, http://www.minister.immi.gov/media/ media-releases/2007/ka07104.htm (accessed 14 August 2009).

6. O. A. Eno and M. Eno, "The Making of the Modern Diaspora: The Resettlement Process of the Somali Bantu Refugees in the United States," in African Minorities in the New World, ed. T. Falola and N. Afolobi (New York: Routledge 2008).

7. D. Ransford, "From 'There' to 'Here': An Investigation of the Initial Settlement Experiences of Ethiopian and Somali Refugees in Toronto," GeoJournal 56, no. 1 (2002): 3-14.

8. C. McMichael and S. M. Gifford, "Narratives of Sexual Health Risk and Protection amongst Young People from Refugee Backgrounds in Melbourne, Australia," Culture, Health and Sexuality, iFirst http://dx.doi .org.10.1080.13691050903359265 (2009) (accessed 28 July 2010).

9. C. McMichael and L. Manderson, "Somali Women and Well-Being: Social Networks and Social Capital among Immigrant Women in Australia," Human Organization 63, no. 1: 88-99.

10. S. Dhanji, "Welcome or Unwelcome?: Integration Issues and the Resettlement of Former Refugees from the Horn of Africa and Sudan in Metropolitan Melbourne, Australasian Review of African Studies 30, no. 2 (2009): 152-178, http://search.informit.com.au/documentSummary;dn $=286153207416332 ;$ res=IELNZC (accessed 28 July 2010); A. Tefera, "The Struggles of Resettlement," Synergy 2,
Multicultural Mental Health Australia, http://www.mmha .org.au/mmha-products/synergy/2007-no-2-resettlement/ the-struggles-of-resettlement/ (accessed 15 May 2008).

11. Department of Immigration and Citizenship, Australia, http://www.immi.gov.au/visas/humanitarian/offshore (accessed June 2010).

12. Department of Immigration and Citizenship, Australia, b, http://www.immi.gov.au/living-in-australia/delivering -assistance/government-programs/settlement-prorams/ ihss.htm (accessed 10 June 2010).

13. Department of Immigration and Citizenship, Australia, http://www.immi.gov.au/visas/humanitarian/offshore (accessed June 2010).

14. Ibid.

15. E. Pittaway and C. Muli, "We Have a Voice Hear Us: An Examination of the Resettlement Experience of Refugees from the Horn of Africa in Sydney," (Sydney: Horn of Africa Relief and Development Agency/Centre for Refugee Research, 2009).

16. J. W. Creswell, Qualitative Inquiry and Research: Choosing among Five Traditions (Thousand Oaks, CA: Sage Publications, 1998), 15.

17. D. Ezzy, Qualitative Analysis (Crows Nest, NSW: Allen \& Unwin, 2002).

18. J. W. Ife, Human Rights from Below: Achieving Rights through Community Development. (Melbourne: Cambridge University Press, 2009);

19. A. Bryman, Social Research Methods (Oxford: Oxford University Press, 2001); S. Sarantakos, Social Research, $2^{\text {nd }}$ ed. (London: Macmillan, 1998).

20. V. Robinson, "Defining and Measuring Successful Refugee Integration," in Proceedings of ECRE International Conference on Integration of Refugees in Europe (Antwerp and Brussels: ECRE, 1998), 18

21. S. Castles, M. Korac, E. Vasta, and S. Vertovec, "Integration: mapping the field" [doc] (London: Home Office), http:// www.homeoffice.gov.uk/rds/pdfs2/rdsolr2803.doc (accessed 14 August 2009).

22. ICMPD Integration Agreements and Voluntary Measures. Compulsion or voluntary nature-comparison of compulsory integration courses, programmes and agreements and voluntary integration programmes and measures in Austria, France, Germany, the Netherlands and Switzerland; ICMPD (2005), http://research.icmpd.org/1301.html (accessed 14 August 2009).

23. Commission on Integration and Cohesion-Our Shared Future http://fra.europa.eu/fraWebsite/research/ publications/publications_per_year/2008/pub_tr _communitycohesion_08_en.htm (2008); Castles, Korac, Vasta, and Vertovec; The Hague Program European Union five year plan 2004, http://www.migrationinformation.org/ Feature/display.cfm?ID=768 (accessed 14 August 1 2009).

24. P. H. Cheong, R. Edwards, H. Goulbourne, and J. Solomons, "Immigration, Social Cohesion and Social Capital: A Critical Review," Critical Social Policy 27, no. 1 (2007): 24-49. 
25. J. Letki, "Does Diversity Erode Social Cohesion? Social Capital and Race in British Neighbourhoods," Political Studies 56, no. 1 (2008): 99-126.

26. UNHCR, The State of the World's Refugees: Human Displacement in the New Millennium (Oxford: Oxford University Press, 2006).

27. A. Ager and A. Strang, "Understanding Integration: A Conceptual Framework," Journal of Refugee Studies 21, no. 2 (2008): 166-191.

28. Ibid., 169.

29. Ibid., 186.

30. The Victorian Foundation for Survivors of Torture (VFST).

31. R. M. Krufeld and L. A. Camino, eds., Reconstructing Lives, Recapturing Meaning: Refugee Identity, Gender, and Cultural Change (Washington, DC: Gorden and Breach, 1994) ix.

32. S Casimiro, P. Hancock, and J. Northcote, "Isolation and Insecurity: Resettlement Issues among Muslim Refugee Women in Perth, Western Australia," Australian Journal of Social Issues 42, no.1 (2007): 56.

33. Ager and Strang, 166-191.

34. Pittaway and Muli.

Eileen Pittaway, PhD, is the director of the Centre of Refugee Research, University of New South Wales, and coordinates the Master of Social Development and the Master of Refugee and Forced Migration. Chrisanta Muli, PhD, lead research advisor, OXFAM Australia, and Sarah Shteir, research assistant, Asia Pacific Civil-Military Centre of Excellence, worked as research associates with the Centre on this project, undertaking both empirical research and the writing. The authors also would like to thank Andrew Sankoh and Rebecca Eckert, who were part of the research team. Without all of their work, the report on which this paper is based would not have happened. We would also like to thank the Horn of Africa Relief and Development Agency (HARDA), which commissioned the research and worked tirelessly to ensure it was a success. Most importantly thanks to all the refugees who so courageously shared their stores, and who contribute so much to Australian society.

This paper is dedicated to Hassan Omar, the instigator of this project and a man who worked ceaselessly for communities from the Horn of Africa i living in Australia. He died unexpectedly and tragically early before the project could be completed. This project is one of many gifts that he has left for the people he so willingly served. It was an honour to work with him.

(C) Eileen Pittaway, Chrisanta Muli and Sarah Shteir, 2009. This open-access work is licensed under a Creative Commons AttributionNonCommercial 4.0 International License, which permits use, reproduction and distribution in any medium for non-commercial purposes, provided the original author(s) are credited and the original publication in Refuge: Canada's Journal on Refugees is cited. 